\title{
O Magmatismo Alcalino Neoproterozóico na llha do Cardoso, Sudeste do Estado de São Paulo
}

\author{
Werner Weber ${ }^{1}$; Miguel A.S. Basei ${ }^{2}$; O swaldo Siga Jr. ${ }^{2} \&$ Kei Sato ${ }^{3}$ \\ 1Pós-graduação Programa Geoquímica e Geotectônica - Instituto de Geociências - USP \\ Rua do Lago 562, CEP 05508-900, São Paulo, SP \\ ${ }^{2}$ Departamento de Mineralogia e G eotectônica - Instituto de Geociências - USP \\ ${ }^{3}$ Centro de Pesquisas Geocronológicas - Instituto de G eociências - USP
}

Palavras Chave: Magmatismo Alcalino, Neoproterozóico, Ilha do Cardoso.

\begin{abstract}
RESUMO
O objetivo deste trabalho é o estudo geológico e geocronológico da Ilha do Cardoso, localizada no litoral sudeste do Estado de São Paulo, divisa com Estado do Paraná. Trata-se de uma área com aproximadamente $151 \mathrm{~km} 2$, de proteção ambiental (APA), administrada pelo Instituto Florestal da Secretaria do Meio Ambiente do Estado de São Paulo. Seu relevo é montanhoso atingindo a cota máxima de 814 metros, sendo recoberta por uma densa vegetação de mata atlântica.

Os terrenos pertencentes a Ilha do Cardoso, são constituídos em grande parte por um complexo ígneo, representado principalmente por rochas sieníticas de cor cinza clara, leucocráticas, inequigranulares e de granulação média a grossa. Composicionalmente predominam sienitos constituídos por piroxênios, hornblendas, e microclíneo pertítico a mesopertítico, exibindo estruturas típicas do fluxo magmático e denominado de Sienito Três Irmãos (STI). Este é cortado por um álcali-feldspato granito com hornblenda e biotita, de cor cinza-rosada, leucocrático de granulação média, denominado de Granito Cambriú (GC).
\end{abstract}

As análises geoquímicas efetuadas nos STI e GC, permitiram atribuir-lhes uma filiação alcalina e meta-aluminosa sugestivas de granitos anorogênicos a tardi orogênicos. Os dados geocronológicos indicam para a formação desses corpos um intervalo de idades entre 620-570 Ma (método U-Pb em zircões), e com o resfriamento entre 597-531 Ma (dados KAr em anfibólios). Análises Sm-Nd em rocha total, realizadas nestas rochas, indicaram idades (TDM) situadas entre o Mesoproterozóico - GC - e o Paleoproterozóico - STI - (1.500 - 2.200 Ma).

Na porção setentrional da Ilha ocorre uma faixa de rochas metassedimentares de baixo grau metamórfico, estruturadas segundo a direção geral E-W. Predominam quartzo xistos, mica-quartzo xisto e quartzo-mica xistos muitas vezes com andaluzita e cordierita. Os dados geocronológicos, Sm-Nd (TDM), sugerem rochas fontes derivadas do manto durante o Paleoproterozóico (1.800-2.200 Ma). Rochas similares ocorrem a oeste, no continente, na região de Taquari, estendendose para sul como faixas relativamente estreitas, em meio aos granitóides do Domínio Paranaguá.

Keywords: Alkaline, Magmatism, Neoproterozoic, Cardoso Island.

\begin{abstract}
This work focuses on the geology and geochronology of rocks cropping out on Cardoso Island, on the southeastern coast of São Paulo State, close to the boundary with Paraná State. The island, with an area of about $151 \mathrm{~km}^{2}$ is a protected area administered by the Forest Institute of the Secretariat for the Environment of the State of São Paulo. It is mountainous, with a peak at $814 \mathrm{~m}$, and is covered by dense "Atlantic Forest" vegetation. The island is made up mainly of an igneous complex with light grey leucocratic, inequigranular, medium to coarse-grained syenites. The Três Irmãos Syenite (STI), composed of pyroxene, hornblende, and perthitic to mesoperthitic microcline, predominates has magmatic flow structures, and is cut by the pinkish grey, leucocratic medium-grained Cambriú alkali-feldspar granites (GC).

Geochemical analysis of STI and GC demonstrate their metaluminous alkaline nature and late orogenic to anorogenic character. The bodies formed between 620 and $570 \mathrm{Ma}$ according to U-Pb dating of zircons and cooled between 597 and $531 \mathrm{Ma}$ (K-Ar in amphiboles). Whole rock Sm-Nd analyses yield Meso - and Paleoproterozoic TDM ages (1,500 - 2,200 Ma). A belt of low-grade metasedimentary rocks occurs in the northern part of the island. Quartz schist, quartz-mica schist and mica-quartz schist, often-containing andalusite and cordierite, predominate.Geochemical and geochronological data suggest that the sources of the metasediments were continental arc andesites of whose protoliths separated from the mantle between 1,800 and 2,200 Ma during the Paleoproterozoic. These metasediments probably continue on the continent in the Taquari region and extend southwards in narrow strips between the granitoids of the Paranaguá Domain.
\end{abstract}




\section{INTRODUÇÃO}

Este trabalho iniciou-se em 1996, tendo como objetivo principal o estudo geológico-geocronológico dos terrenos pertencentes a Ilha do Cardoso, instalada na porção oriental do Domínio Paranaguá.

A Ilha do Cardoso localiza-se no litoral do Estado de São Paulo divisa com o Estado do Paraná, abrangendo uma área de aproximadamente $151 \mathrm{~km}^{2}$ (Figura 1). Tratase de uma Área de Proteção Ambiental (APA) administrada pelo Instituto Florestal da Secretaria de Meio Ambiente do Estado de São Paulo. Exibe uma densa e exuberante vegetação de Mata Atlântica, que serve de habitat a uma rica fauna representada por capivaras, catetos, jaguatiricas, jacarés, entre outros. Apresenta relevo em grande parte montanhoso atingindo a cota máxima de 814 metros. A ilha exibe uma densa rede de drenagem, na sua maioria rios e riachos perenes, expressivos manguezais e a sul uma restinga de aproximadamente $18 \mathrm{~km}$ de extensão por 500 metros de largura.
Os terrenos pertencentes a Ilha do Cardoso são representados em grande parte por rochas de natureza alcalina, sienitos e alcali-granitos, que ocupam uma área de aproximadamente $68 \mathrm{~km}^{2}$. Esses litotipos mostram na porção setentrional, contatos intrusivos com uma faixa de metassedimentos (quartzo-xistos, mica-xistos e mica-quartzo-xistos) estruturados com direção aproximada E-W (Figura 2). As pesquisas geológicas envolveram trabalhos de campo e coleta de amostras, algumas orientadas para estudos estruturais, geocronológicos, geoquímicos e petrológicos. O estudo geocronológico envolveu os métodos U-Pb em concentrados de zircões, Sm-Nd (TDM em rocha total), K-Ar (anfibólios e rocha total) e $\mathrm{Rb} / \mathrm{Sr}$ (em rocha total) com o intuito de obter informações relativas às épocas de diferenciação manto-crosta dos protólitos crustais dessas rochas, bem como das épocas de formação e resfriamento das mesmas. O estudo petrológico e geoquímico (elementos maiores, traços e terras raras) permitiram a melhor caracterização dos litotipos mapeados, dando adicionalmente suporte às análises geocronológicas.

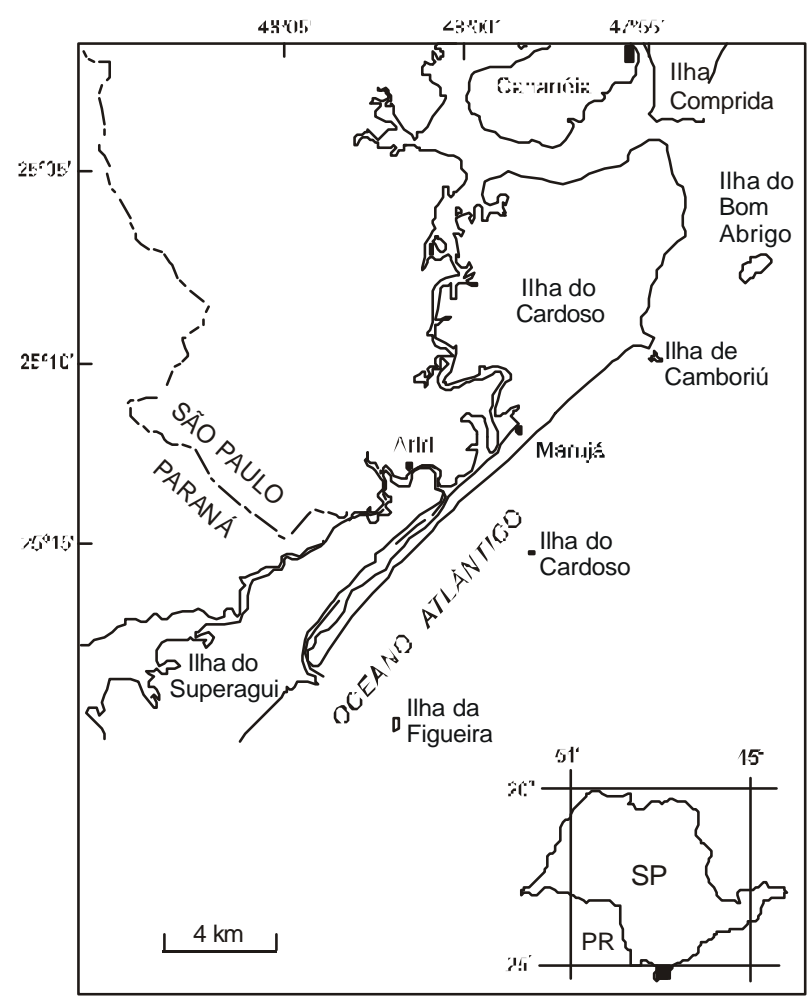

Figura 1: Localização da área. 


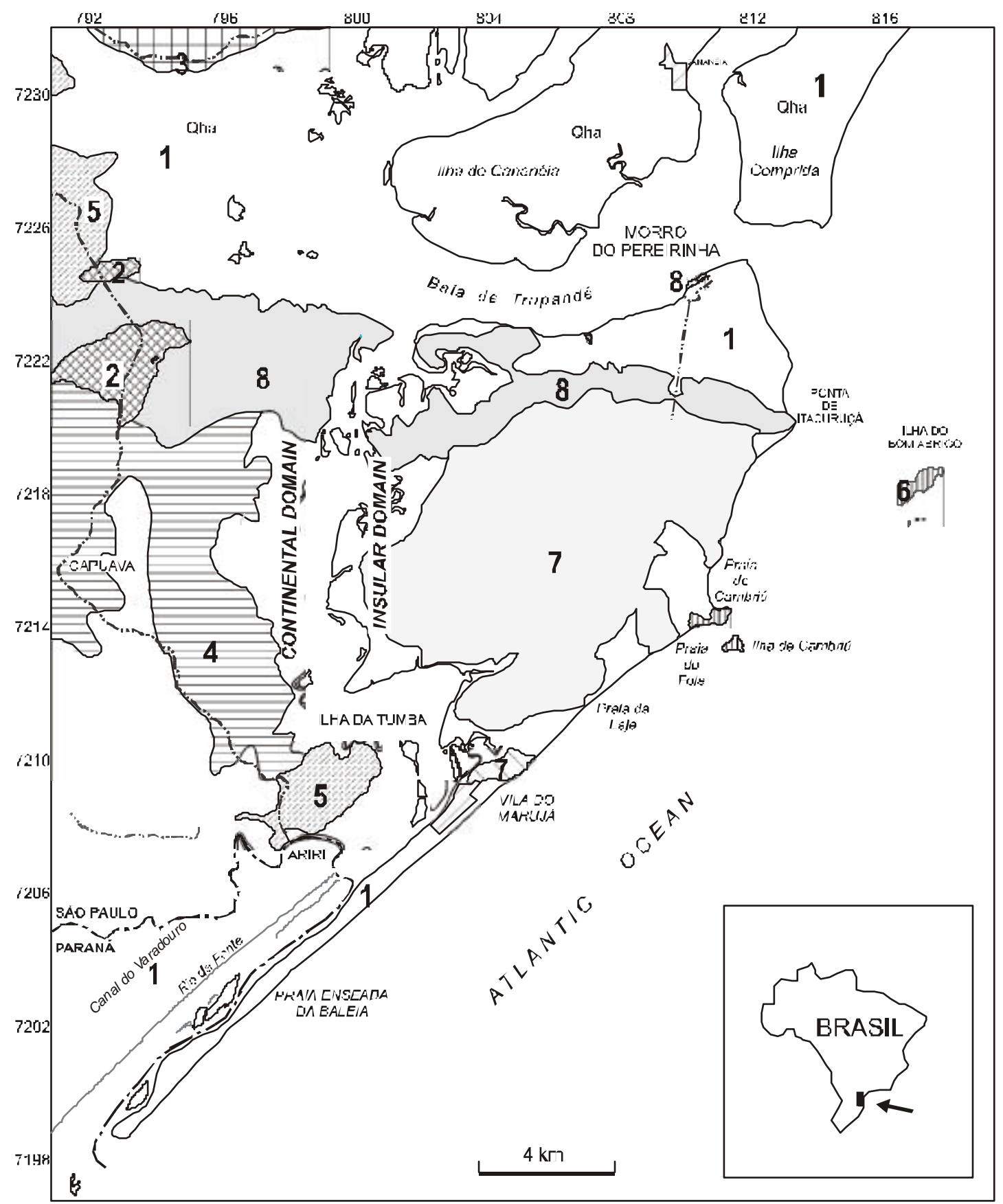

1 SEDIMENTOS QUATERNÁRIOS

2 FORMAÇÃO PARIQUERA AÇU (Pleistoceno)

5 AMFIBOLIO/BIOTITA GNAISSES

3. ALCALI-FELDSPATO GRANITO ITAPITANGU (Granito Mandira)

[6] ALCALI-FELDSPATO GRANITO CAMBRIÚ (GC)

7 ALCALI-FELDSPATO SIENITO TRÊS IRMÃOS (STI)

E 4 GRANITOS PORFIRÍTICOS (Domínio Paranaguá)

8 ROCHAS METASSEDIMENTARES (Mica Xistos,
Qzo xistos e Mica-Qzo xistos; com Andaluzita e Cordierita)

Figura 2: Mapa geológico simplificado. 


\section{TRABALHOS ANTERIORES}

A bibliografia relacionada aos terrenos pertencentes a Ilha do Cardoso é bastante escassa, caracterizada por abordagens restritas, envolvendo poucos dados de campo e/ou laboratoriais incluídos em trabalhos de cunho regional.

Trabalho pioneiro foi realizado na Ilha de Cananéia, adjacente à Ilha do Cardoso, por Freitas (1947), que identificou duas famílias de rochas alcalinas representadas por pulaskitos e nordmarkitos.

Posteriormente, Amaral (1967) realizaram datações KAr em alcali-feldspato, barkevicita e biotita de um nordmarquito, coletado por Freitas (op.cit.) em Cananéia. As idades obtidas foram respectivamente de $84 \mathrm{Ma}, 82$ Ma e $81 \mathrm{Ma}$, resultando em uma idade média de $82 \mathrm{Ma}$. Estes dados foram recalculados por Sonoki \& Garda (1988), utilizando-se das novas constantes geocronológicas em vigor, resultando em uma idade média de 83,5 Ma.

Kutner (1962) descreve a existência de uma lage no canal de Cananéia e supõe ser a ligação entre o maciço alcalino de Cananéia e o Morrete na Ilha Comprida. As rochas que ocorrem no Morrete da Ilha Comprida foram caracterizadas petrograficamente por Coutinho (1972), como quartzo sienitos (nordmarkitos).

As seqüências sedimentares cenozóicas da planície costeira entre Cananéia e Iguape foram estudadas por Suguio \& Petri (1973), utilizando-se de sondagens mecânicas, executadas em 1966 pelo instituto geográfico e geológico. Mencionam que o embasamento Proterozóico é composto por filitos, mica xistos, migmatitos e gnaisses.

A primeira descrição das rochas ígneas que ocorrem no domínio da Ilha do Cardoso foi realizada por Cordani \& Bittencourt (1967). Caracterizam a ocorrência de granitos intrusivos no complexo migmatítico indiferenciado com idade K-Ar em anfibólio de $610 \pm 20 \mathrm{Ma}$.

Em 1969, Petri \& Fúlfaro correlacionam as rochas metassedimentares aflorantes na Ilha do Cardoso às seqüências por eles descritas na região de Apiaí-Iporanga sugerindo ambiente de sedimentação de águas rasas.

Petri \& Fúlfaro (1970), descrevem os metassedimentos que ocorrem no setor setentrional da Ilha do Cardoso como metaritmitos, caracterizados pela alternância de níveis francamente psamíticos (areias), e níveis pelíticos (silto-argiloso). Mencionam a presença de estruturas sedimentares preservadas (estratificação cruzada e laminações cruzadas por migração de ondas) principalmente nos níveis arenosos grossos. Os mesmos autores estimaram para o pacote metassedimentar, a espessura de 5.000 metros, desconsiderando a perturbação tectônica.
Eventos relacionados ao Quaternário da planície costeira do sul do Estado de São Paulo são discutidos por Suguio \& Petri (1973), com ênfase as areias regressivas tipo "sheet sands", que constituem uma fonte importante de detritos para os sub-ambientes atuais. Os mesmos autores, utilizando-se de dados obtidos através de levantamentos geofísicos, executados entre a Ilha Comprida e a Ilha do Cardoso, descrevem a existência de um desnivelamento entre esta última e o continente. Tal desnivelamento foi interpretado como um mergulho natural (1/100) do embasamento da região, rumo ao oceano.

Martin \& Suguio (1975), sugerem para o setor costeiro de São Paulo movimentos tectônicos relativamente fracos durante o Holoceno e mais intensos durante o Pleistoceno, o que explicaria o comportamento diferenciado entre a costa sudeste, com características de emersão, em relação a costa nordeste, com características de imersão.

Morgental etal.(1975), descrevem as rochas graníticas da Ilha do Cardoso como 'atípicas', classificando-as petrográficamente como plauenitos e álcali sienitos, sugerindo tratar-se de rochas formadas através da diferenciação de corpos alcalinos. Sugerem a realização de datações geocronológicas adicionais para melhor definir a colocação crono-espacial dessas rochas alcalinas. Através dos dados geocronológicos existentes estes autores correlacionam as rochas alcalinas da Ilha do Cardoso ao Maciço granítico Alto Turvo.

Silva et al. (1981), correlacionam os metassedimentos da Ilha do Cardoso à seqüência Turvo- Cajati, posicionando-os na sub-sequiência Cajati, de caráter rítmico, com passagem gradativa para a sub-seqüência Turvo - Areado. Os mesmos autores atribuem a esses metassedimentos predominantemente clasto-química, origem vulcano-sedimentar, de idade transamazônica. Sugerem ainda a possibilidade das rochas alcali sieníticas que ocorrem na Ilha do Cardoso estarem relacionadas temporalmente ao corpo alcalino de Cananéia. Aconselharam estudos mais detalhados de campo e principalmente geocronológicos.

Ulbrich \& Gomes (1981), descrevem as rochas que ocorrem em Cananéia como uma associação sienítica saturada a subsaturada, predominando álcali sienitos, pulaskitos e nefelina sienitos com mineralogia típica de suítes miaskíticas, segundo Sorensen (1974).

Suguio et al. (1987) utilizando-se de perfilagens geofísicas realizadas entre a Ilha de Cananéia e a Ilha Comprida, definem o contorno para a lage do Argolão, um afloramento rochoso testemunho da ligação entre o morro de São João (Cananéia) e o morrete (Ilha Comprida). 
Riccomini (1995) constata que o padrão de fraturamento NE-SW relativo às rochas alcalinas que ocorrem em Cananéia é coerente com o observado para o alinhamento Guapiara. Sugere regime de esforços trativos modificando-se, provavelmente no Eoceno, para transcorrente sinistral, com compressão NE-SW e extensão NW-SE e a conseqüente colocação de diques de lamprófiro.

Souza e Souza et al. (1996) utilizando-se de dados geológicos e geofísicos, admitem um condicionamento tectônico para o arcabouço estrutural da planície costeira Cananéia - Iguape.

\section{GEOLOGIA DA ÁREA}

A Ilha do Cardoso é constituída predominantemente por um complexo ígneo representado por rochas sieníticas (aegirina/augita-hornblenda-álcali-feldspato-sienito), leucocráticas de cor cinza clara, inequigranulares, com granulação que varia de média a grossa. Estruturalmente exibe uma orientação de fluxo magmático dado pelo alinhamento de fenocristais de feldspato potássico e anfibólio.

A textura é normalmente, hipidiomórfica e os minerais predominantes são: microclíneo, micro a mesopertítico ( $50 \%)$, e oligoclásio que raramente ultrapassa os $10 \%$. O principal mineral máfico presente é o anfibólio (15$20 \%$ ), representado por cristais de hornblendas, de coloração castanha a verde e tons verde-azulado. O piroxênio ( 10\%) é representado por aegirina-augitas idiomórficas, muitas vezes alteradas, gerando como produto opacos e biotitas/anfibólios em pequenos núcleos. O quartzo presente se distribui em pequenos grãos na matriz ou então como intercrescimento mimerquítico, e raramente ultrapassa $10 \%$ em volume da rocha. Os minerais acessórios mais comuns são representados pela apatita, epídoto geralmente granular e associado a transformação de anfibólios; titanita ( 5\%) idiomórfica; opacos (hipidiomórficos) e zircão, idiomórfico, biterminado, prismático com uma relação 3:1 e incolor. As rochas acima descritas foram neste trabalho denominadas de Sienito Três Irmãos (STI), em função de sua maior representatividade na localidade homônima.

Estas rochas sieníticas (STI) ocorrem como enclaves sub-arredondados a angulosos, além de serem cortados por álcali-feldspato granitos de cor cinza-rosada, leucocrática, textura inequigranular e granulação média, denominados de Granito Cambriú (GC), em função de suas melhores exposições ocorrem na localidade homônima. Em seções delgadas predominam nessas rochas o micro- clíneo normalmente hipidiomórfico com geminação em grade $(\sim 55 \%)$, quartzo $(\sim 20 \%)$, oligoclásio $(<5 \%)$, ocorrendo em maior ou menor proporção a hornblenda e a biotita como principais minerais máficos. Os minerais acessórios mais comuns são apatita, zircão, opacos e titanita.

A porção setentrional da Ilha do Cardoso é representada por uma faixa de rochas metassedimentares. São compostas por quartzo-mica xisto, mica xisto e mica-quartzo xisto muitas vezes com andaluzita e cordierita.

Esses metassedimentos têm como características gerais bandamento ritmico, representado por intercalações de níveis francamente pelíticos e de níveis francamente psamíticos, sendo comum a presença de estratificações cruzadas de baixo ângulo, granodecrescência e estruturas plano paralela que caracterizam S0. Cristais de sericita e biotita orientados parlela a subparalelamente ao acamamento, definem uma superfície metamórfica S1 de baixo grau metamórfico. Esta superfície encontra-se crenulada e paralelamente aos planos axiais destas dobras, ocorre a formação de uma superfície metamórfica S2, plano axial muito bem evidênciada de direção preferencial E$\mathrm{W}$, com eixos subhorizontais e caimento preferencialmente para E. O metamorfismo atuante nestes metassedimentos atingiu no máximo a fácies xisto verde zona da biotita. A presença freqüente de andaluzitas sugerem que as pressões se mantiveram abaixo de $4 \mathrm{~kb}$ e as temperaturas atingiram valores da ordem de no máximo $500{ }^{\circ} \mathrm{C}$. A cordierita ocorre localizadamente e as relações de campo e petrográficas, indicam que estas possam ter sido originadas pelo aporte de calor relacionado a colocação do corpo sienítico, nitidamente intrusivo nos metassedimentos. Esta intrusão teria ocorrido tardi a pós o desenvolvimento da deformação geradora da superfície S2. Ainda, a possibilidade dos fenocristais de andaluzita representarem produto de metamorfismo de contato não encontra suporte, uma vez que encontram-se generalizadamente distribuidos nos metassedimentos, e indicam crescimento sin a deformação que gerou a superfície metamórfica S2.

\section{ANÁLISE ESTRUTURAL}

A principal feição estrutural observada em grande parte dos afloramentos relacionados às rochas ígneas da Ilha do Cardoso refere-se a orientação de certos minerais, a exemplos de anfibólios e de fenocristais de feldspato potássico, sugestivos de fluxo magmático.

Nas rochas metassedimentares, a presença de bandamento rítmico, caracterizado pela alternância de níveis pelíticos e níveis psamíticos, estratificações cruzadas, granodecrescencia, dobras convolutas e estruturas 
plano paralelas identificam a superfície primária S0. Planos milimétricamente espaçados, subparalelos a superfície primária que em campo muitas vezes se confundem com S0, nos quais desenvolvem-se cristais de sericitas e biotitas orientandas que definem a superfície $\mathrm{S} 1$, gerada em condições metamórficas de baixo grau, fácies xisto verde zona da clorita/biotita. Em rochas psamíticas essa superfície é de difícil identificação.

A superfície (S1) mostra-se heterogeneamente deformada, apresentando-se ora crenulada ora dobrada, e neste caso geram por vezes dobras D2 abertas, cilíndricas, e ocasionalmente dobras fechadas, tendendo a isoclinais. Observa-se uma clivagem de crenulação diferenciada, plano axial a essas dobras, onde desenvolvem-se cristais de biotitas, sericitas/muscovitas, quartzos e andaluzitas.

No estereograma da Figura 3, encontram-se representados os pólos relativos a medidas realizadas ao longo de uma superfície dobrada (plano AC), juntamente com o plano axial e eixos. A guirlanda construída retrata o padrão de dobramento (D2) observado neste afloramento, apresentando direção geral $\mathrm{N} 20^{\circ} \mathrm{E} / 45^{\circ} \mathrm{SE}$ (com máximo $\mathrm{N} 63^{\circ} \mathrm{E} / 74^{\circ} \mathrm{NW}$ ) e com eixos subhorizontais e caimento preferencialmente para $\mathrm{E}$.

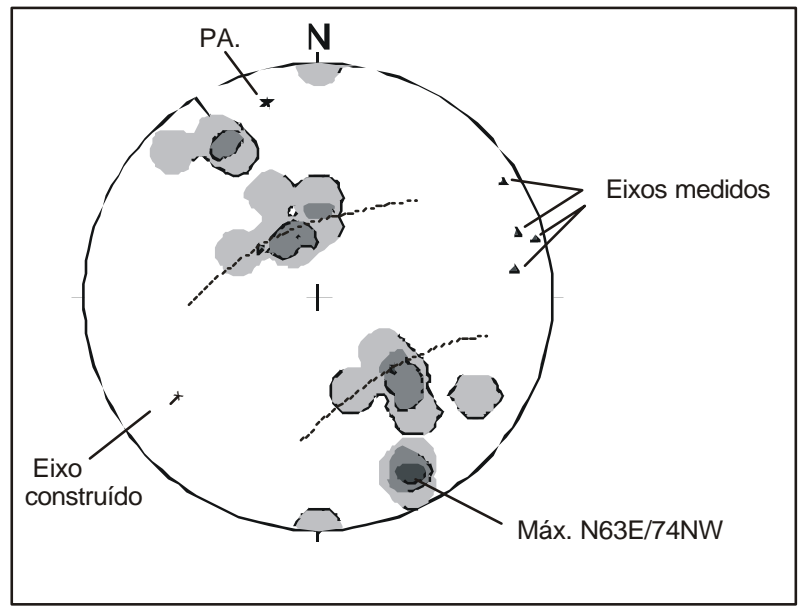

Figura 3: Estereograma 2 - medidas ao longo dos flancos de dobras abertas do afloramento WW-11 (número de medidas: 22 , intervalo entre as curvas $5 \%$ ).

A Figura 4 reúne as projeções polares das superfícies S0//S1 relativo aos demais afloramentos visitados. Observa-se uma concentração de pólos nos extremos $\mathrm{N}$ e $\mathrm{S}$ do diagrama, sugestivos de dobramentos relativamente fechados, isoclinais, com máximo segundo E-W/84 ${ }^{\circ} \mathrm{N}$.

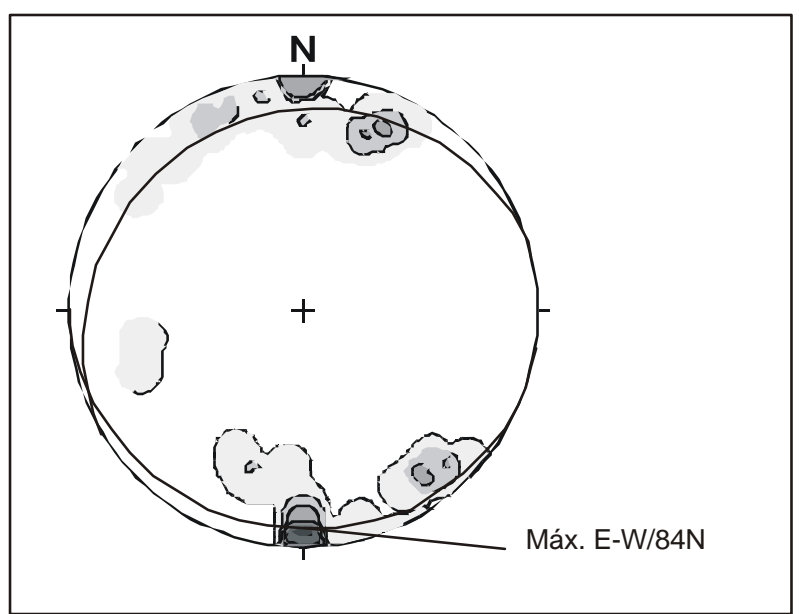

Figura 4: Estereograma 3 - medidas de S1/S0 (número de medidas: 46 , intervalo entre curvas $4 \%$ ).

Adicionalmente os diagramas das figuras 3 e 4, apresentam uma relativa dispersão dos pólos S0//S1 ao longo de superfícies aproximadamente E-W. Tal dispersão é sugestiva de dobramentos abertos, amplos, de caráter regional (D3), não observados em afloramentos. O eixo construído apresenta direção geral N-S, coincidente com planos de clivagens espaçados, observados principalmente no afloramento WW-11 e, refletem ao nosso ver dobramentos (D3) amplos, tardios e de caráter regional.

\section{GEOQUÍMICA}

Com intuito de melhor caracterizar os litotipos aflorantes na Ilha do Cardoso, foram analisadas 17 amostra pelo método ICP-MS junto ao Activations Laboratory - ACTLABS - Canadá, relativas as rochas sieníticas (10 amostras do STI), e do alcali granito Cambriú (3 amostras do GC) bem como das sequências metassedimentares (4 amostras), envolvendo elementos maiores, traços e terras raras.

As rochas ígneas pertencentes aos STI e GC quando analisadas no diagrama QAP (Figura 5) com os campos de distribuição das séries granitóides (segundo Lameyre \& Bowden, 1982), indicam para o primeiro composição quartzo sienítica a álcali-feldspato sienítica e para o segundo composição álcali-feldspato granítica, ambos com afinidades alcalinas a peralcalinas. Os índices de aluminosidade (Mainar \& Piccoli, 1989), denotam características predominantemente meta aluminosas para estas rochas ígneas (Figura 6). 


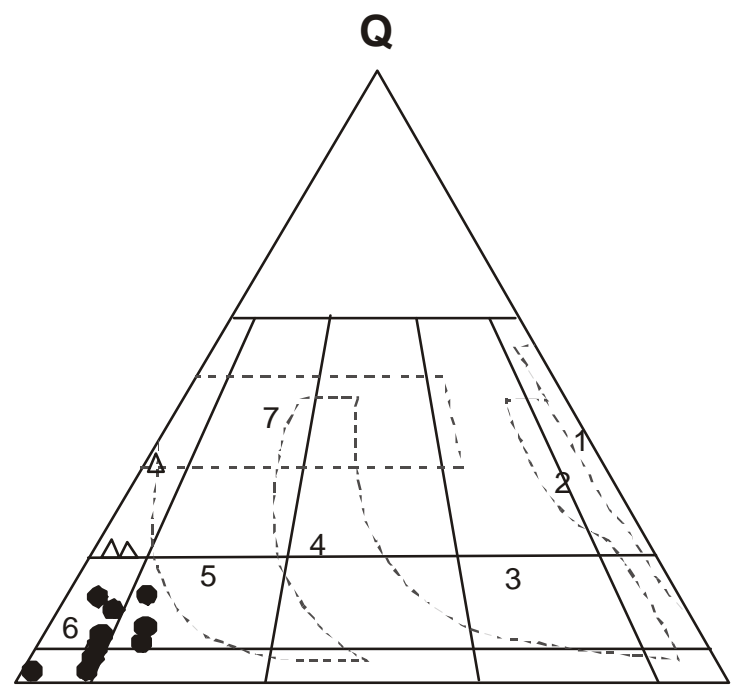

A

Figura 5: Diagrama Q AP com os campos de distribuição das séries granitóides (segundo Lameyre \& Bowden, 1982)- campos: 1- Toleítico; 2- Cálcio-alcalinotrondjemítico (baixo K); 3- Cálcio-alcalinogranodioritico (médio K); 4- Cálcio alcalinomonzonítico (alto K); 5- Granitóides aluminosos de províncias alcalinas; 6- Alcalino e peralcalino; 7Recobrimento de granitóides por fusão crustal (circulos - STI; triângulos - GC).

Em diagrama multicatiônico R1 x R2 (De La Roche, 1980) com os campos de Batchelor \& Bowden (1985) (Figura 7) os dados analíticos relativos as rochas ígneas denotam afinidade sub - alcalina a alcalinas, e mostram uma concentração no campo referente aos granitos tardiorogênicos a anorogênicos.Observa-se também neste diagrama relativa dispersão dos pontos referentes aos sienitos STI, possivelmente relacionada a teores bastante variados nos elementos Fe e Ti, sugerindo tratar-se de associação intermediária entre alcalina e sub - alcalina. Adicionalmente observa-se pontos analíticos distribuidos a esquerda da bissetriz que limita os campos no diagrama R1 x R2, provavelmente são super saturadas em alcalis. De um modo geral os poucos dados relativos aos GC, atestam uma tendência alcalina.

O padrão observado para os elementos terras raras (ETR), ressalta o comportamento geoquímico entre as rochas ígneas analisadas (STI e GC). Observa-se um fracionamento relativamente forte entre os ETRL e ETRP, mais expressivo no STI (Figura 8). O padrão serrilhado observado nos ETRP, possivelmente pode estar refletindo

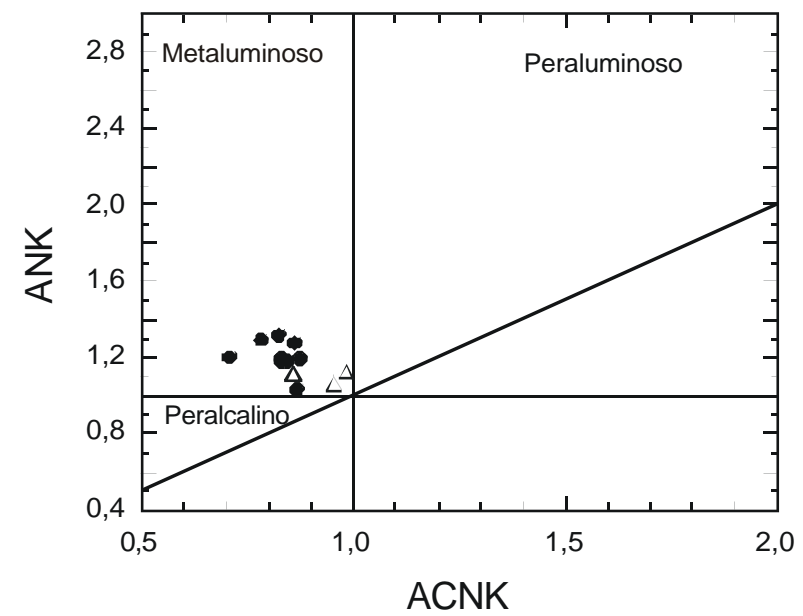

Figura 6: Diagrama de índice de aluminosidade (Mainar \& Piccoli, 1984), para as rochas STI (círculos) e GC (triângulos).

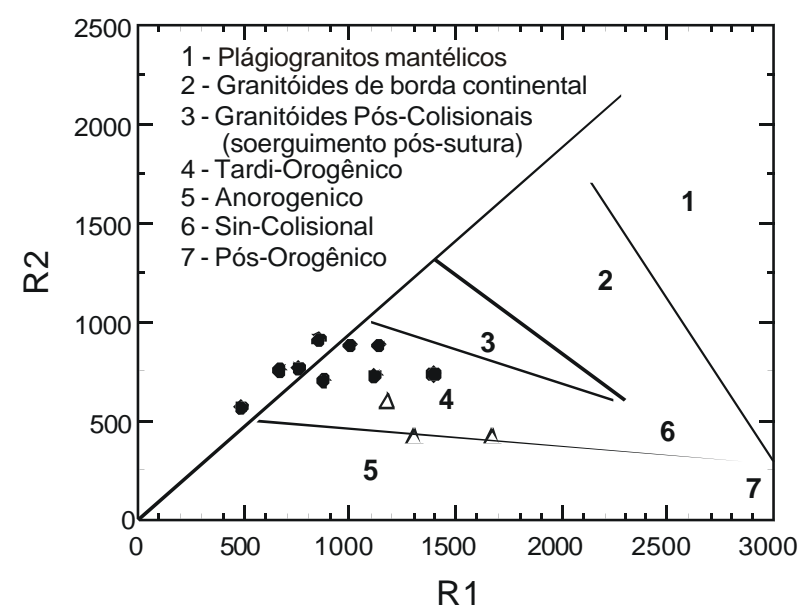

Figura 7: Diagrama R1xR2 (De La Roche etal., 1980). Campos segundo Batchelor e Bowden (1985). 


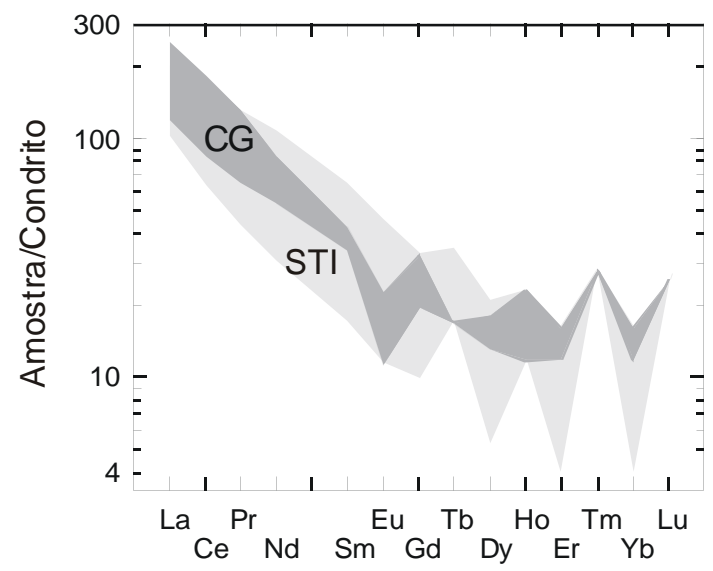

Figura 8: Padrões de terras raras para amostras da llha do Cardoso, simbologia idem as figuras anteriores (STI- Sienito Três Irmãos; GC-Granito Cambriú).

problemas analíticos, pois o padrão não é muito comum. Adicionalmente ocorre uma forte depleção do elemento Eu nos GC, sugerindo importante papel do feldspato nos processos de cristalização fracionada, distintamente dos STI, onde o anfibólio (hornblenda) parece ter tido papel preponderante.

Para as rochas metassedimentares foram considerados apenas os dados referentes aos elementos terras raras (ETR). De um modo geral, observa-se um expressivo fracionamento entre os ETRL e os ETRP (Figura 9). A forte depleção de Ce observada, notadamente nos níveis de granulação mais fina podem estar refletindo condições de intemperismo através de processos de lixiviação desse elemento. Por tratarem-se de rochas metassedimentares, que podem envolver diferentes fontes do sedimento, bem como processos intempéricos diferenciados, seriam necessárias analises adicionais para uma melhor caracterização genética desse material.

\section{GEOCRONOLOGIA}

Os estudos geológicos preexistentes contavam com apenas um dado geocronológico relativo a um granitóide analisado pelo método K-Ar em anfibólio, que acusou idade de $610 \pm 20$ Ma (Cordani \& Bittencourt, 1967).

Interessante é que na Ilha de Cananéia, situada a poucos kilometros $(\sim 5 \mathrm{Km})$ da Ilha do Cardoso, ocorrem rochas de natureza alcalina, representadas por pulaskitos e nordmarkitos, estudadas por Freitas (1947), que caracterizou esses ultimos litotipos como tardios na evolução

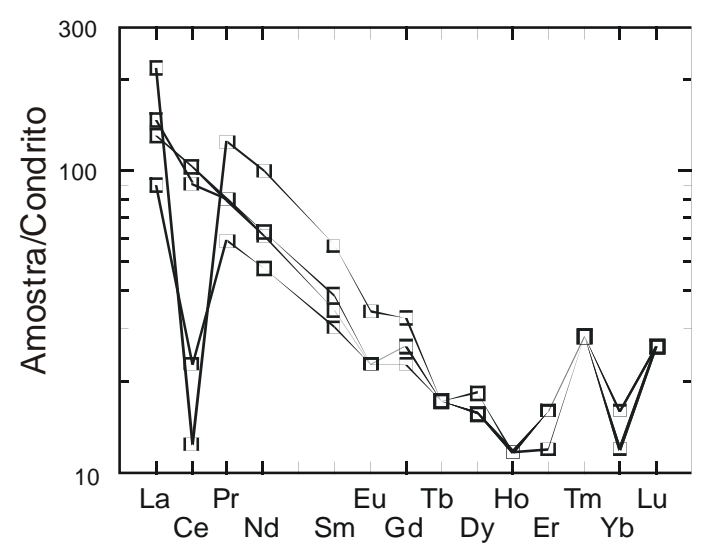

Figura 9: Padrão de terras raras para os xistos da llha do Cardoso.

desse complexo ígneo. Os nordmarkitos foram datados através do método K-Ar em alcali - feldspato, barkevicita e biotita, apresentando idades bastante próximas, ao redor de 83,5 Ma (Amaral et al.,1967a; Sonoki \& Garda, 1988). Acrescente-se que as idades modelo Sm-Nd (TDM ) relacionadas a época de derivação do manto superior dos protólitos dessas rochas resultaram em idades ao redor de 1.235 Ma (Weber, 1998).

Na contra parte continental, âmbito do Dominio Paranaguá, ocorre uma variedade de granitóides cujas idades de formação são relativas ao Neoproterozóico. Os valores obtidos por Siga Jr. (1995) apresentam intervalo de idades bastante amplo, desde sua formação (U-Pb: 620 - $600 \mathrm{Ma}$ ), fechamento do sistema isotópico Rb-Sr (600 $570 \mathrm{Ma})$, e resfriamento regional (K-Ar: 560 - $480 \mathrm{Ma}$ ). Acrescente-se que as idades modelo Sm-Nd (TDM ) relacionadas a época de derivação do manto superior dos protólitos crustais desses granitóides, concentram-se entre 2.200 e $1.900 \mathrm{Ma}$ (granitóides tipo Morro Inglês) com valores isolados em 2.400 Ma (granitóide Canavieiras) e $2.600 \mathrm{Ma}$ (granitóides tipo Estrela).

As determinações radiométricas realizadas em rochas graníticas e metassedimentares pertencentes aos domínios da Ilha do Cardoso, envolveram os métodos Sm-Nd em rocha total (TDM ), U-Pb em zircões e K-Ar em minerais, além de análises $\mathrm{Sr}$-Sr de seqüências metassedimentares. Tal estudo, aplicando metodologias de distintos valores interpretativos, embora preliminar, teve por objetivo caracterizar não só a época de formação e resfriamento dessas rochas e de seus protólitos crustais, mas também os possíveis reservatórios que contribuiram para a formação de crosta continental. 
O maciço cienítico Três Irmãos (STI), quando analisado através do método U-Pb em zircões, indicou valores Neoproterozóicos. Foram analisadas quatro frações de zircões, relativas a dois afloramentos (WW-46 e WW-75), cujas populações desses minerais mostram-se muito similares, com cristais prismáticos, biterminados, translúcidos e isentos de inclusões e farturas. Três desses dados posicionam-se próximos a curva concórdia, definindo, quando forçada á origem, a idade de $622 \pm 19 \mathrm{Ma}$, interpretada como relativa à época de cristalização do zircão (Figura 10). O ponto analítico referente a fração nm-5 (afloramento de número de campo WW-46) posicionouse relativamente afastado dos demais, não denotando boa colinearidade a eles. A única análise K-Ar realizada, refere-se a concentrados de hornblenda da rocha sienítica de número de campo WW-46, que acusou uma idade de 597 $\pm 14 \mathrm{Ma}$. Tal valor relaciona-se ao resfriamento dessas rochas, sugerindo intervalo relativamente curto, levandose em conta a diferença mínima, entre a formação e o soerguimento à isotermas superiores a $500{ }^{\circ} \mathrm{C}$ (temperatura inferiores a $500{ }^{\circ} \mathrm{C}$ ).

Adicionalmente, foi realizada uma análise $\mathrm{Sm}-\mathrm{Nd}$ (TDM) em rocha total, que acusou idade de $2030 \pm 56$ $\mathrm{Ma}$, relacionada à época de derivação do manto superior dos protólitos desses sienitos.

Os álcali-feldspato granitos (GC), tipo Cambriú, tardios na história evolutiva desse magmatismo, quando analisados através do método U-Pb em zircões, têm idade de $567 \pm 15$ Ma (Figura 11). Tratam-se de zircões prismáticos longos, biterminados com faces e arestas bem desenvolvidas, em geral com inclusões fluidas. Distinguem-se daqueles concentrados nos STI, por apresentarem tonalidades castanho claro e mostram-se normalmente fraturados. As frações analisadas m -2, m -3 e m -4, relativas ao álcali feldspato granito com número de campo WW-79, da localidade de Cambriú, apresentam-se relativamente bem alinhados e distribuídos em diagrama concórdia, e a idade obtida (567 $\pm 15 \mathrm{Ma})$ é aqui interpretada como relativa a época de cristalização do zircão.

Análise K-Ar realizada em concentrados anfibólios da amostra desse mesmo afloramento, indicou idade de 531 $\pm 5 \mathrm{Ma}$, relativo ao resfriamento destas rochas.

A metodologia Sm-Nd quando aplicada a essas rochas, resultou em idade modelo (TDM) de $1.536 \pm 49 \mathrm{Ma}$, (o afloramento da Ponta do Cambriú: WW-79), valor este indicativo da época de diferenciação do manto superior, dos protólitos deste álcali-granito. Tal idade difere muito da obtida para os STI $(2030 \pm 56 \mathrm{Ma})$ sugerindo fontes distintas na gênese destas rochas. Acrescente-se aqui que dados adicionais são necessários para uma melhor caracterização dessa idade modelo, uma vez que não deve ser

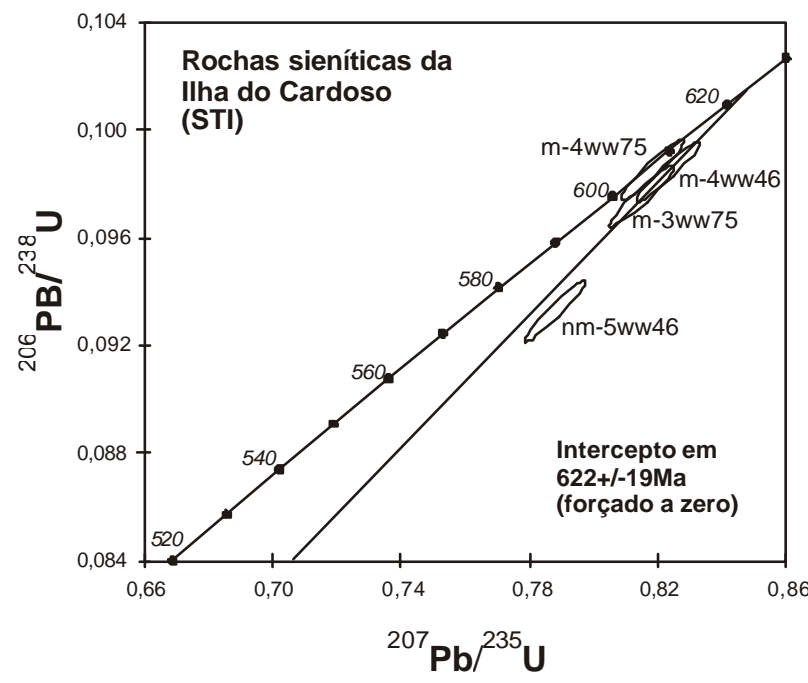

Figura 10: Diagrama concórdia U-Pb em zircões do STI.

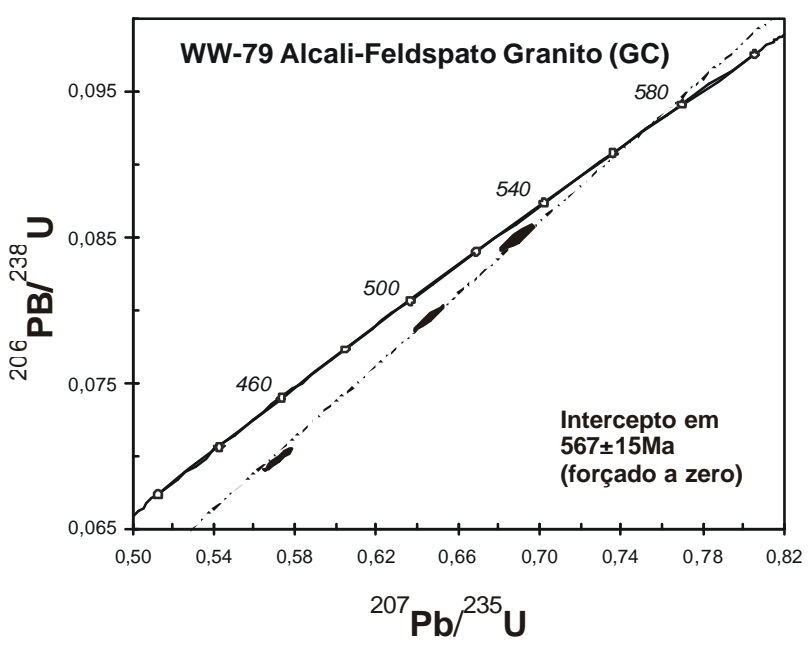

Figura 11 : Diagrama concórdia U-Pb em zircões do GC. 
descartada a possibilidade de mistura de magmas.

Nas figuras 12 e 13 encontram-se representados os valores de eNd versus $\mathrm{T}(\mathrm{Ga})$, para as rochas ígneas e os xistos respectivamente. Análises $\mathrm{Sm}-\mathrm{Nd}$ realizadas em níveis pelíticos das sequências metassedimentares acusaram idades entre $2.200-1.800 \mathrm{Ma}$. Tais valores refletem acerca dos processos crustais da(s) rocha(s)- fonte que deram origem aos metassedimentos. Sugerem épocas relacionadas ao Paleoproterozóico para derivação do manto superior do material fonte, embora tal contribuição possa estar relacionada a mistura da então bacia sedimentar, de rochas distintas, com idades modelo diferentes.

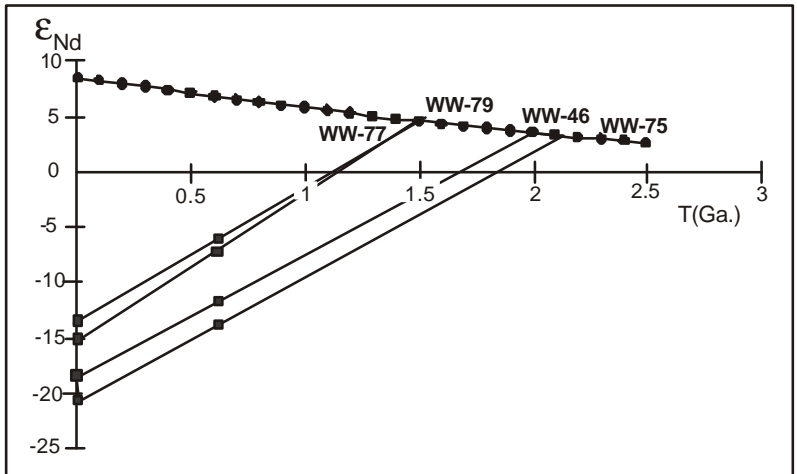

Figura 12: Diagrama de evolução isotópica e $\mathrm{Nd}$ versus tempo geológico $\mathrm{T}(\mathrm{G}$ a) das rochas ígneas de afinidade alcalina da Ilha do Cardoso.

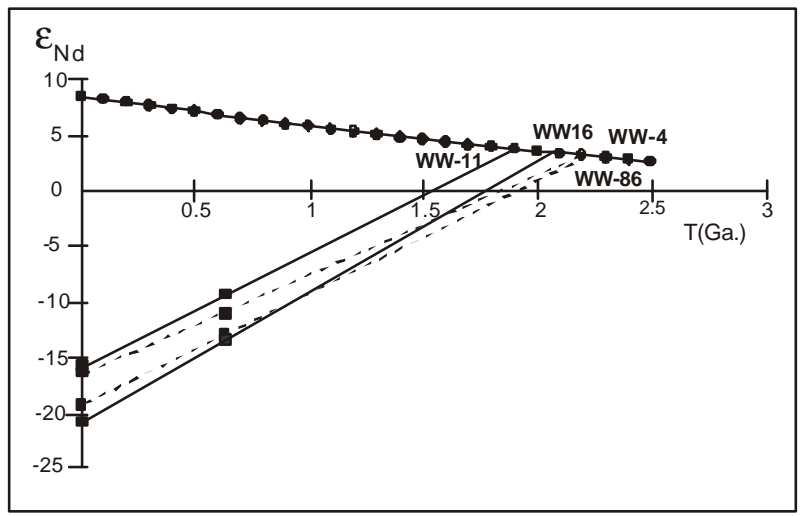

Figura 13: Diagrama de evolução isotópica e $\mathrm{Nd}$ versus tempo geológico $\mathrm{T}(\mathrm{G} a)$ dos xisto aflorantes na llha do Cardoso.

\section{CONSIDERAÇÕES FINAIS E CONCLUSÕES}

Os terrenos pertencentes a Ilha do Cardoso são constituídos em grande parte por um complexo ígneo representado por rochas de natureza sienítica (STI), que se mostram cortadas e invadidas por rochas de filiação granítica de natureza alcalina (GC). A porção setentrional da ilha é representada por uma faixa de rochas metassedimentares de baixo grau metamórfico, onde predominam quartzoxistos, mica-quartzo-xistos e quartzo-mica-xistos, muitas vezes com andaluzitas e, notadamente próximo ao contato com o complexo ígneo, portador de cordierita.

O magmatismo mais antigo (idade de formação de 622 \pm 19 Ma e resfriamento de $597 \pm 14 \mathrm{Ma}$ ) é representado principalmente por rochas com composições quartzosieniticas a álcali-feldspato sieniticas (STI), enquanto no mais jovem (idade de formação de $567 \pm 15 \mathrm{Ma}$ e resfriamento de $531 \pm 5 \mathrm{Ma}$ ) predominam composições álcali-feldspato graníticas (GC). Denotam características predominantemente meta-aluminosas e afinidades a alcalinas, sugestivas de magmatismo de natureza tardiorogênica a anorogênica.

No diagrama eNd x tempo (Figura 12) podemos visualizar os diferente padrões que envolvem os STI e o $\mathrm{GC}$, indicativos de materiais fontes distintos na origem desses conjuntos magmáticos. As idade modelo (TDM) obtidas de 2030 e 1536 Ma caracterizam diferentes épocas relacionadas à diferenciação do manto superior dos protólitos crustais que originaram essas rochas, e os valores de eNd (calculadas para época de formação dessas rochas) se mostram bastante negativos, respectivamente de $-13,99$ e - 7,12, denotando tempo de residência crustal relativamente longo.

Além do que, o posicionamento dos dados analíticos no IV quadrante do diagrama eNd x eSr (Figura 13) sugere tratarem-se de rochas formadas no Neoproterozóico a partir do retrabalhamento de materias crustais.

As rochas sieníticas (STI) mostram-se na porção setentrional da ilha, intrusivos nas sequências metassedimentares, com características estruturais tardi a pós $\mathrm{S} 2$, possívelmente sin S3 .

As idades Sm-Nd (TDM) obtidas para esses metassedimentos distribuem-se no intervalo 2.200-1.800 Ma, relacionadas ao Paleoproterozóico. Refletem acerca da diferenciação do manto superior dos protólitos, que serviram de fonte na formação destas rochas. A possibilidade de esses valores representarem misturas de materiais oriundos de fontes distintas, não pode ser descartada.

No diagrama eNd x tempo (Figura 15) podemos 
visualizar o padrão evolutivo do $\mathrm{Nd}$, que mostra valores de eNd negativos $(-9,28$ e -13,45) no Neoproterozóico. O posicionamento dos dados analíticos no IV quadrante do diagrama eNd x eSr (Figura 14) caracteriza a sua origem crustal.

As rochas ígneas e metamórficas observadas na Ilha do Cardoso, apesar de suas particularidades, integram possivelmente os Terrenos do Domínio Paranaguá (Basei et al., 1992 e Siga Jr., 1995) diferindo significativamente dos principais blocos tectônicos conhecidos na região tais como Bloco Apiaí, Luiz Alves e Curitiba.

A relação geológica entre os terrenos da ilha e do continente, sugere possível continuidade nos metassedimentos da ilha com rochas similares, que desde a região de Pariqüera-Açu, estendem-se para sul ao longo de toda porção litorânea até a região de Guaraqueçaba e Paranaguá, onde Lopes (1987) descreve a formação Rio das Cobras. Esses metassedimentos se mostram como faixas estreitas e alongadas, sugerindo que sua distribuição esteja condicionada a grandes lineamentos com direção NE-SW.

Finalmente, com intuito de melhor caracterizar aspectos relacionados a evolução crustal da região pesquisada e do sul-sudeste brasileiro (sudeste de São Paulo a Nordeste de Santa Catarina), envolvendo os Domínios Paranaguá, Luís Alves e Curitiba, foram analisados os valores disponíveis de eNd em função das idades de formação dos diferentes tipos de rocha deste setor (Figura 15).

Observa-se durante o Neoproterozóico, um amplo intervalo de distribuição dos valores negativos de eNd, sistematicamente negativos (-7 a -23), indicando que os processos de formação de rocha, deste período, envolveram predominantemente o retrabalhamento de material com vida crustal pretérita. Nota-se que a grande maioria desse material foi formado durante o Neoproterozóico e indica, através de idades modelo $\mathrm{Sm}-\mathrm{Nd}$, épocas de diferenciação do manto superior relativo ao Paleoproterozóico. O padrão relativo aos terrenos sul africanos (Harris et al., 1986), se distingue do observado na Figura 15, principalmente por caracterizar volumes significativos de rochas formadas durante o Mesoproterozóico. Acrescente-se que na porção sul africana, a distribuição dos valores de eNd durante o Neoproterozóico se assemelha ao do setor sul sudeste brasileiro, evidenciando, adicionalmente, acreção do manto superior neste período.

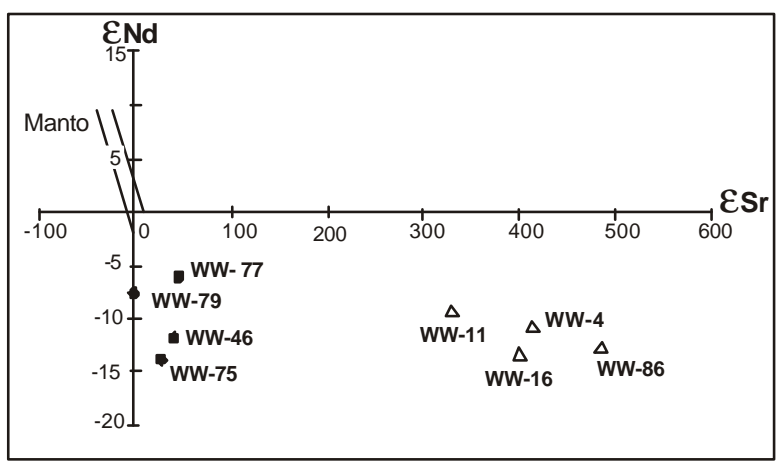

Figura 14: Diagrama e $\mathrm{Nd}(\mathrm{t})$ versus e $\mathrm{Sr}(\mathrm{t})$ para $\mathrm{t}=0.62$ $\mathrm{G} a$, onde os pontos pretos representam as amostras dos corpos ígneos e os triângulos são amostras dos xistos aflorantes na llha do Cardoso.

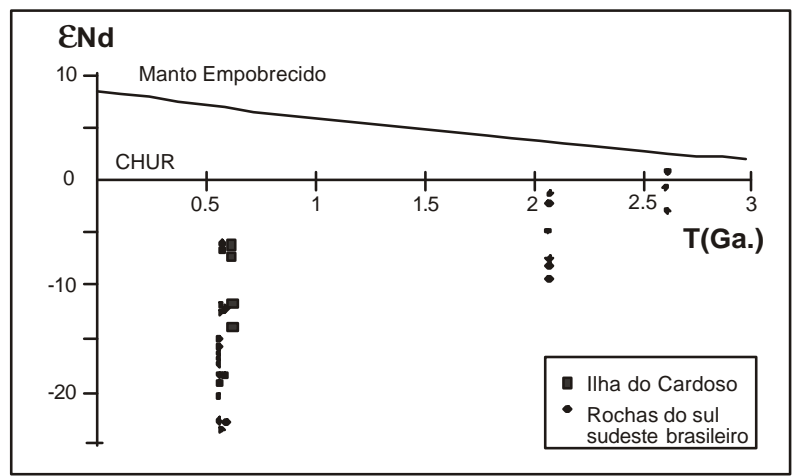

Figura 15: Diagrama de evolução isotópica e $\mathrm{Nd}$ versus tempo geológico $\mathrm{T}(\mathrm{G}$ a) das rochas ígneas de afinidade alcalina da Ilha do Cardoso (Q uadrados), e de rochas da região sul - sudeste brasileiro (pontos).

\section{REFERÊNCIAS BIBLIOGRÁFICAS}

AMARAL, G.; BUSHEE, J.; CORDANI, U.G.; KAWASHITA, K.; REYNALDS, J.H. (1967) Potassium-argon ages of alkaline rocks from southern Brazil. Geochimica et Cosmochimica Acta, v. 31, p.117-142.

AMARAL, G.; CORDANI, U.G.; KAWASHITA, K.; REYNOLDS, J.H. (1967) Potassium-Argon dates of basaltics rocks from southern Brazil. Geochimica et Cosmochimica Acta, v. 30, n. 2, p.159-189. 
BARCELOS, J.H. (1975) Sedimentação e subambientes deposicionais da Ilha Comprida, São Paulo. São Paulo, 155p. Dissertação (Mestrado) - Instituto de Geociências, Universidade de São Paulo, São Paulo.

BASEI, M.A.S.; SIGA Jr., O.; REIS NETO, J.M. (1990) O Batolito Paranaguá. Proposição, idade, considerações petrogenéticas e implicações tectônicas. In: CONGRESSO BRASILEIRO DE GEOLOGIA, 36, Natal. Anais. Natal, SBG. v. 4, p. 1684-1699.

BASEI, M.A.S.; SIGA Jr., O.; MACHIAVELLI, A.; MANCINI, F. (1992) Evolução tectônica dos terrenos entre os Cinturões Ribeira e Dom Feliciano (PR SC). Revista Brasileira de Geociências, v. 22, n. 2, p. 216-221.

BASEI, M.A.S.; SIGA JUNIOR, O.; SATO, K.; SPROESSER, W.M. (1995) A metodologia UrânioChumbo na Universidade de São Paulo. Princípios metodológicos, aplicações e resultados obtidos. Anais da Academia Brasileira de Ciências, v. 67, n. 2, p. 221-237.

BATCHELOR, R.A. ; BOWDEN, P. (1985) Petrogenetic interpretation of granitoid rocks series using multicationic parameters. Chemical Geology, v. 48, n. $1 / 4$, p. $43-55$.

BHATIA, M.R.; CROOK, K.A.W. (1986) Trace element characteristics of graywackes and tectonic discrimination of sedimentary basins. Contributions to Mineralogy and Petrololy, v. 92, p. 181-193.

BHATIA, M.R. (1983) Plate tectonics and geochimical composition of sandstones. Journal of Geology, v. 91, p. 611-627.

BOWDEN, P.; TURNER, D.C. (1974) Peralkaline and associated Ring Complex in the Nigeria - Niger Province, West Africa. In: SORENSEN, H. (ed.). The alkaline rocks. New York, J. Wiley \& Sons, p. 330351 .

BOWDEN, P.; BATCHELOR, R.A.; CHAPPEL, B.W.; DIDIER, J.; LAMEYRE, J. (1984) Petrological, geochemical and source criteria for the classification of granitic rocks: a discussion. Physics of the Earth and Planetary Interiors, v. 35, n. 1/3, p.1-11.

CORDANI, U.G. ; HASUI, Y. (1969) Idades K-Ar de rochas alcalinas do primeiro planalto do Estado ddo Paraná. In: CONGRESSO BRASILEIRO DE GEOLOGIA, 22., Belo Horizonte, 1969. Anais. Belo Horizonte, SBG. v 2, p. 149-153.

CORDANI, U.G. (1970) Idade do vulcanismo no Oceano Atlântico Sul. Boletim IGA, n. 1, p. 9-75.
CORDANI, U.G.; BITTENCOURT, I. (1967) Determinações de idade potássio-argônio em rochas do Grupo Açungui. In: CONGRESSO BRASILEIRO DE GEOLOGIA, 21, Curitiba, 1967. Anais. Curitiba, SBG. p. 218-223.

COUTINHO, J.M.V. (1972) Petrologia do Pré-Cambriano em São Paulo e arredores. Boletim IG-USP, n. 3, p. 3-100.

ERICKSSON, K.A.; SOEGAARD, K. (1985) The petrografy and geochemistry of Archean and Early Proterozoic sediment: implication of crustal compositions and surface processes. Geological Survey of Finland, n. 331.

FAURE, G. (1986) Principles of isotope geology. New York, John Wiley \& Sons. 589p.

FREITAS, R.O (1947) Eruptivas alcalinas de Cananéia, Estado de São Paulo. Boletim. Faculdade de Filosofia, Ciências e Letras da Universidade de São Paulo. Serie Geologia, v. 4, p. 1-35.

HARRIS,N.B.W.;PEARCE, J.A.; TINDLE, A.G. (1986) Geochemical characteristic of collision-zone magmatism. In: COWARD, M.P. ; RIES, A.C. (eds). Collision tectônics. p.67-81. London, Geological Society. (Geological Society Special Publications, 18).

KAWASHITA, K.; SONOKI, I. K.; SATO, K.; SONOKI, H. M. (1990) Regressões lineares em geocronologia: isócronas, errócronas e pseudo-isócronas. Boletim IG-USP, Série Científica, n. 21, p. 53-72.

KUTNER, A. S. (1962) Granulometria dos sedimentos de fundo da região de Cananéia, SP. Boletim da Sociedade Brasileira de Geologia, v. 2, n. 2, p. 4154.

LAMEYRE, J; BOWDEN, P. (1982) Plutonic rocks types series: discrimination of various granitoid series and related rocks. Journal of Volcanology and Geothermal Research, v. 14, n. 1/2, p.169-186.

LOPES, O.F. (1987) Zoneamento metamórfico da Formação Rio das Cobras do pré-cambriano do Estado do Paraná. In: SIMPÓSIO SULBRASILEIRO DE GEOLOGIA, 3, Curitiba. Atas. Curitiba, SBG. v. 1, p. 303-312.

LOPES, O.F.; LIMA, R.E. (1985) Evolução geológica da Formação Rio das Cobras no leste do Estado do Paraná. In: SIMPÓSIO SUL-BRASILEIRO DE GEOLOGIA, 2., Florianópolis. Atas. Florianópolis, SBG. p.53-60.

MANIAR, P.D.;PICCOLI, P.M. (1989) Tectonic discrimination of granitoids. Geological Society American Bulletin, v. 101, p. 635-643. 
MARTIN, L. ; SUGUIO, K. (1975) The state of São Paulo costal Marine Geology - "the ancient strand lines". Anais da Academia Brasileira de Ciências. Suplemento, v. 47, p. 249-263.

MORGENTAL, A.; BATOLLA JR., F.; PINTO,G.G.; PAIVA, I.P.; DRUMOND, B.V. (1975) PROJETO Sudelpa: geologia. São Paulo, CPRM. v. 1. ( relatório final )

PEARCE, J.A.; HARRIS, N.B.W.; TINDLE, A.G. (1984) Trace element discrimination diagrams for the tectonic interpretation of granitic rocks. Journal of Petrology, v. 25, p. 956-983

PETRI, S.; FÚlFARO, V.J. (1969) Sobre os metassedimentos do Açungui do extremo sul do Estado de São Paulo. São Paulo, DAEE-USP. 81p.

PETRI, S.; FÚLFARO, V.J. (1970) Nota sobre geologia e terraços marinhos da Ilha do Cardoso. Noticia Geomorfologica, v. 20, n. 10, p. 21.

PETRI, S.; SUGUIO, K. (1973) Stratigrafy of the IguapeCananéia lagoonal region sedimentary deposits, São Paulo state, Brazil. Part II: heavy minerals studies, microorganisms inventories and stratigraphical interpretations. Boletim IG-USP, v. 4, p. 71-85

RICCOMINI, C. (1995) Padrão de fraturamentos do maciço alcalino de Cananéia, Estado de São Paulo: relações com a tectônica mesozóico-cenozóica do sudeste do Brasil. Revista Brasileira de Geociências, v. 25, n. 2, p. 7 9-84.

SATO, K.; TASSINARI, C.C.G.; KAWASHITA, K.; PETRONILHO, L. (1995) O método geocronológico Sm-Nd no IG/USP e suas aplicações. Anais da Academia Brasileira de Ciências, v. 67, n. 3, p. 315-336.

SIGA Jr., O. (1995) Domínios tectônicos do sudeste do Paraná e nordeste de Santa Catarina: geocronologia e evolução crustal. São Paulo, 212p. Tese (Doutorado) - Instituto de Geociências, Universidade de São Paulo.

SIGA Jr, O ; BASEI, M.AS.; REIS NETO, J.M.; HARARA, O.M.M.; PASSARELI, C.R.;PRAZERES FILHO, H.J.; WEBER, W.; MACHIAVELLI, A. (1997) Ages and tectonic setting of alkalineperalkaline granitoids of Paraná and Santa Catarina States, southern Brazil. In: SOUTH-AMERICAN
SYMPOSIUM ON ISOTOPE GEOLOGY, Campos do Jordão, 1997. Extended Abstracts. Campos de Jordão, FAPESP/CNPq/CPRM, p. 301-303.

SILVA, A. T.S. F. (1981) Tentativa de interpretação da gênese e evolução da infraestrutura arqueana exposta entre Peruíbe e Curitiba, SP e PR. In: SIMPÓSIO REGIONAL DE GEOLOGIA, 3, Curitiba, 1981. Atas. Curitiba, SBG. v. 1, p. 133-147

SILVA, A.T.S. da; FRANCISCONI, O.; GODOY, A.M. de; BATOLLA JR., F. (1981) Projeto integração e detalhe geológico no Vale do Ribeira. São Paulo, DNPM/CPRM. v.1 (relatório final.)

SOUZA, L.A.P.; TESSLER, M.G.; GALLI, V.L. (1996) O grabén de Cananéia. Revista Brasileira de Geociências, v. 26, p. 139-150.

SUGUIO, K.; PETRI, S. (1973) Stratigrafy of the IguapeCananéia lagoonal region sedimentary deposits, São Paulo state, Brazil. Part I: field observations and grain size analisys. Boletim IG-USP, v. 4, p. 1-20.

SUGUIO, K. ;TESSLER, M.G.; FURTADO, V.V.; ESTEVES, C.A.; SOUZA, L.A.P. (1987) Perfilagens geofísicas e sedimentação na área submersa entre Cananéia e Barra de Cananéia (SP) In: SIMPÓSIO SOBRE ECOSSISTEMAS DA COSTA SUL E SUDESTE BRASILEIRA, 1., Cananéia, 1987. Academia de Ciências do Estado de São Paulo. v. 2, p 234-241.

SONOKI, I.K.; GARDA, G.M. (1988) Idades K-Ar de rochas alcalinas do Brasil meridional e Paraguai oriental: compilação e adaptação às novas constantes de decaimento. Boletim. IG-USP. Série Científica, v. 19. p. 63-85.

SORENSEN, H. (1974) The alkaline rocks. New York, John Wiley \& Sons.622p.

STRECKEISEN, A. (1976) To each plutonic rock its proper name. Earth Science Reviews, v. 12, n. 1, p. $1-33$.

ULBRICH, H.H.J.; GOMES, C.B. (1981) Alkaline rocks from continental Brazil. Earth Science Reviews, v. 17 , p. $135-154$.

WEBER, W. (1998) Geologia e geocronologia da Ilha do Cardoso, Sudeste do Estado de São Paulo. São Paulo, 87p. Dissertação (Mestrado) - Instituto de Geociências, Universidade de São Paulo. 